\title{
Study of natural uranium fuel for a new reactor design TEPLATOR
}

\author{
Tomas Peltan ${ }^{1}$, Eva Vilimova ${ }^{1}$, and Radek Skoda ${ }^{1}$ \\ ${ }^{1}$ University of West Bohemia, Faculty of Electrical Engineering, Univerzitni 8, 30100 Pilsen, Czechia \\ peltan@fel.zcu.cz
}

\begin{abstract}
The TEPLATOR is a new type of nuclear reactor which the main purpose is producing heat for district heating. It is designed as a special thermal reactor with $\mathbf{5 5}$ fuel channels for fuel assemblies, which is moderated and cooled by heavy water and operated around atmospheric pressure. The TEPLATOR DEMO is designed for the use of irradiated fuel from PWR or BWR reactors. Using heavy water as the moderator and coolant in this reactor concept allows to use natural uranium as an alternative fuel in case that the irradiated fuel is not available for some reason. This solution is suitable because of the price of natural uranium and the absence of costly fuel enrichment. This article is focused on deeper analyses of alternative suitable fuel for TEPLATOR based on natural uranium and new fuel geometries. This work builds on previous research on alternative fuel material and geometry for the TEPLATOR. It is mainly concerned with the neutronic development of fuel assemblies, the possibility of manufacturing of developed fuel types, and optimization of fuel management and uranium consumption. This article contains predetermined candidates for suitable fuel geometries and new untested fuel geometry types with some new advantages. Finally, optimization of the whole reactor core and number of fuel channels was made in terms of increased safety and higher fuel burn-up. Presented calculations were performed by Monte Carlo code Seprent.
\end{abstract}

Keywords - TEPLATOR, Natural uranium, Serpent code

\section{INTRODUCTION}

$\mathrm{T}_{\mathrm{c}}^{\mathrm{s}}$ HE TEPLATOR is a new reactor concept developed in the Czech Republic for district heating purposes. It is developed in cooperation between the University of West Bohemia in Pilsen and the Czech Institute of Informatics and Cybernetics of the Czech Technical University in Prague. The main purpose is producing only heat energy for district heating or for process heating for different types of factories, for chilling and other uses. The TEPLATOR is developed for using already irradiated VVER-440 fuel, which has optimal burnup [1] . The idea of TEPLATOR works with different spent PWR or BWR fuel types, TEPLATOR DEMO is designed namely with VVER-440 spent nuclear fuel. The reactor contains 55 hexagonal fuel channels where the fuel assemblies are placed. These 55 fuel channels are situated in a calandria filled with heavy water, and the heavy water is used also for cooling of the fuel assemblies. These two loops are separated by fuel channels, which have the same dimension as the VVER-440 fuel. The fuel channel consists of two concentric hexagonal tubes, between these tubes is $\mathrm{CO}_{2}$ as a thermal shielding. Around the heavy water reactor core, a graphite reflector is placed in radial and axial position. TEPLATOR can run with a fresh fuel in VVER-440 geometry, this fuel should be slightly enriched up to $1.2 \%$ of ${ }^{235} \mathrm{U}[1]$.

TEPLATOR DEMO is designed with 50 MWth output power with output temperature of the coolant around $98^{\circ} \mathrm{C}$ with a slightly higher atmospheric pressure. Later, after the DEMO testing, the concept of TEPLATOR aims up to 150MWth TEPLATOR FULL. The operation time of one fuel loading is around 2 years for a 50MW unit with irradiated fuel. The visualization of TEPLATOR DEMO can be seen in Figure 1.

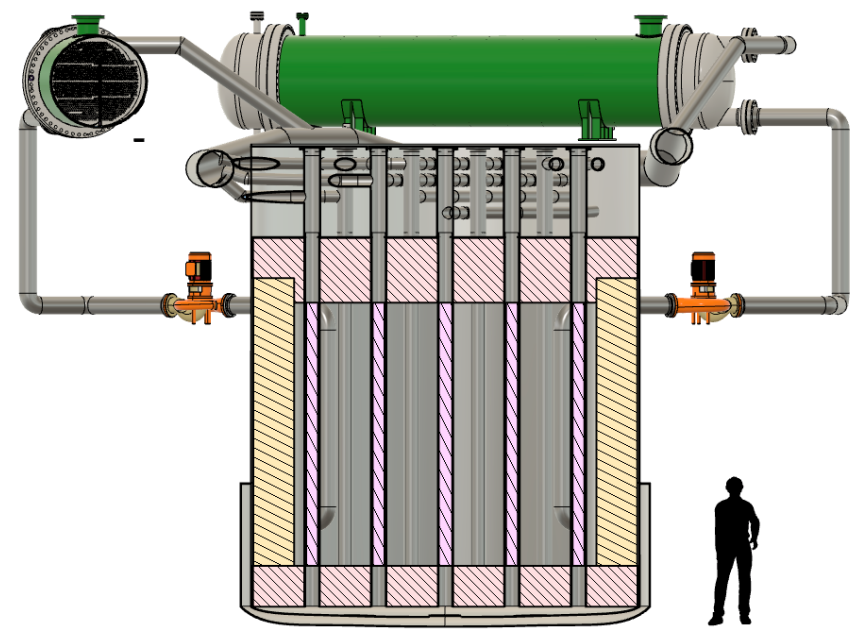

Figure 1. TEPLATOR DEMO layout in comparison with human size - side view.

\section{PRELIMINARY STUDY OF NATURAL URANIUM}

The TEPLATOR is designed with using of heavy water as the coolant and the moderator, which determine possibility of using a natural uranium as an alternative fuel. This solution can be suitable for countries, which do not have an irradiated fuel in storage and for which the enriching of uranium is expensive. Natural uranium is safer than enriched uranium due to possibility of criticality accidents. In previous work [2] , the sets of calculations with different fuel geometries with natural uranium were performed. Based on these results we assume that natural uranium can be used as an alternative fuel for 
TEPLATOR due to sufficient reactivity excess. In previous research work, some suitable fuel geometries were found, and two fuel materials $\mathrm{UO}_{2}$ and metal uranium were tested. During calculations, issues with positive void coefficient were found. This phenomenon was solved by developing a new coolant displacer with special construction features, which mitigates this problem [3] . Developed geometries with promising results are shown in Figure 2.

Two slightly different geometries, tubular and hexagonal tubes, were designed in previous work and this type of fuel was used for the next calculations.

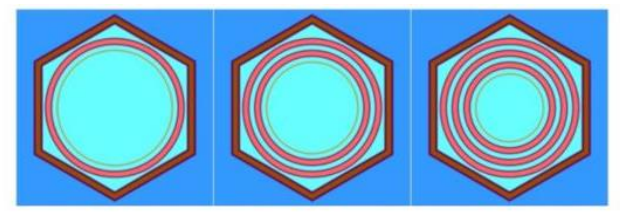

Cylindrical tubes with displacer - one, two and three tube modification

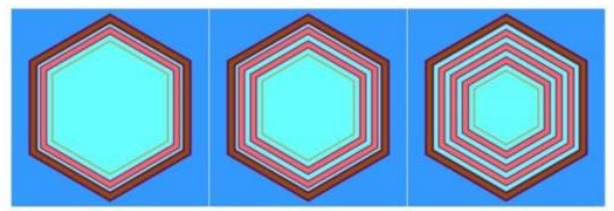

Hexagonal tubes with displacer - one, two and three tube modification Figure 2. Two different geometries of fuel - cylindrical and hexagonal tubes with modifications of fuel tubes.

For safety reasons, this fuel types are crucial to operate it in optimal moderation condition. The optimal moderation condition means that there is no over-moderated arrangement of the reactor core from the $\mathrm{H}_{2} \mathrm{O} / \mathrm{U}$ ratio point of view. The all calculated cases with new developed fuel types in the designed TEPLATOR core layout with 55 fuel assemblies with fuel pitch for irradiated VVER-440 fuel were always slightly over-moderated, which is unacceptable from safety reasons point of view due to positive feedback of reactivity.

\section{OPTIMAL FUEL PITCH CALCULATIONS}

Based on the previous results, all six fuel geometries with the different fuel layer thickness described in [2] were recalculated for finding the optimal fuel channel pitch in the TEPLATOR core. The fuel layer thicknesses were obtained from the previous calculations, and for purposes of this paper, only the layers with the best keff were considered. A few $\mathrm{UO}_{2}$ modifications were recalculated and mainly the modifications with the $\mathrm{U}$ metal fuel layer due to the higher keff and better heat conductivity of metal uranium in thick fuel layers.

The dimensions of the core and the fuel channels are the same as for the VVER-440 irradiated fuel, this study is modification of the designed reactor core of TEPLATOR, not development of a new reactor core. The seven different fuel channels pitches were calculated in step by $5 \mathrm{~cm}$ from $25 \mathrm{~cm}$ to $55 \mathrm{~cm}$. The more precise fuel pitch of the new developed fuel is not part of this paper due to the early stages of the fuel development and the whole reactor arrangement. The construction materials of the cooling channels and the entire reactor, which are now under calculation testing, could affect the moderation properties in the reactor core, so the preliminary fuel pitch is assumed as sufficient. After finding the precise core arrangement, more accurate calculations with other modifications will be performed.

With the decreasing pitch of the fuel channels, the number of fuel assemblies in the reactor core increases, and directly affects the $\mathrm{H}_{2} \mathrm{O} / \mathrm{U}$ ratio. The number of fuel assemblies depending on the fuel pitch can be seen in Table 1 .

TABLE 1. DEPENDENCE BETWEEN THE NUMBER OF FUEL ASSEMBLIES (FA) IN THE REACTOR CORE AND THE FUEL ASSEMBLIES PITCH

\begin{tabular}{c|ccccccc}
\hline \hline Fuel pitch [cm] & 25 & 30 & 35 & 40 & 45 & 50 & 55 \\
\hline Number of FA [-] & 185 & 121 & 87 & 73 & 55 & 43 & 37 \\
\hline \hline
\end{tabular}

An increasing number of the fuel elements in the reactor caused a higher weight of uranium that was used, which can be utilized for heat production. For each fuel geometry modification and for specific fuel layer thickness, the best fuel pitch was chosen. The radial section of the reactor core for imagination shows Figure 3.

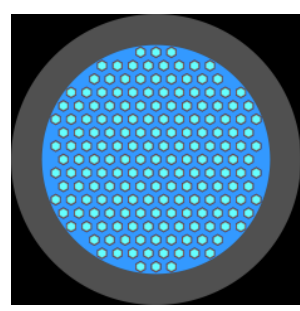

$25 \mathrm{~cm}$ FA pitch

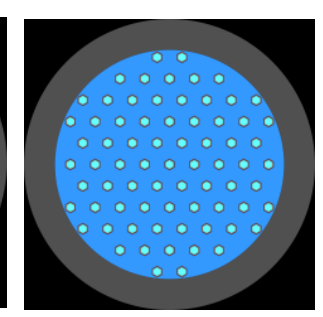

$40 \mathrm{~cm}$ FA pitch

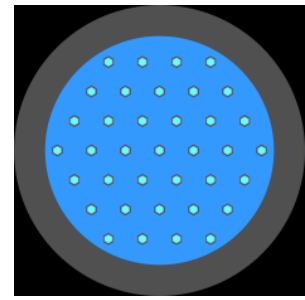

$55 \mathrm{~cm}$ FA pitch
Figure 3. The layout of TEPLATOR core with the different fuel channels pitch

The course of keff depending on the fuel assembly pitch in the TEPLATOR core can be seen in Figure 4 and Figure 5. These courses were made for all six fuel geometry modifications, for each modification just some fuel layers thicknesses were considered.

\section{BURNUP CALCULATIONS AND FUEL UTILIZATION}

After finding an optimal fuel pitch for each fuel modification, the burnup calculation was caried out. The burnup of fuel was calculated with the same steps for all cases, the predefined cumulative burnup sequence was used - butot. Burnup was calculated with 10 radial subdivisions of the fuel layer and with an average power density in the reactor core. The axial subdivision of the fuel was not considered. The output power of reactor was set to $50 \mathrm{MWth}$. The calculation proceeded at least until keff $=1$, then the reactor became subcritical. During burnup the temperature of all materials and fuel was not changed. Obtained result from this type of calculation is average burnup of the fuel in $\mathrm{MWd} / \mathrm{kgU}$ [4] . Higher burnup of the fuel means more utilized fuel and lower price of produced heat.

\section{CALCUlATIONS AND MODELS}

The all mentioned modifications with different fuel pitch were calculated using Serpent 2.1.31 [4] code. For all materials with corresponding temperatures, the ENDF/B-VII.1 [5] 
nuclear data library was used. The Thermal Scattering Library (TSL) for heavy water and for graphite was also obtained from the same nuclear data library. The temperature for all construction materials was conservatively set at $371 \mathrm{~K}$, due to the output temperature of the coolant. The fuel material temperature was set to $600 \mathrm{~K}$, which is relatively close to raw calculations. Temperature of the fuel layer is based on simplified thermohydraulic calculations with $10 \mathrm{~mm}$ thick layer of metal uranium.

Criticality calculations were performed with 20,000 neutrons per generation and 2,000 generations $(2,000$ active plus 100 inactive generations). The resulting standard deviation is below $8 \mathrm{pcm}$ for all cases, which is sufficient in this preliminary study.

After criticality calculations, the cases with designated optimal fuel pitch with the highest keff were burned out. For the burnup calculations, 40,000 neutrons per one generation and 2,000 histories (2,000 active plus 100 inactive histories) were used. The standard deviation of all cases and calculated steps does not exceed $6 \mathrm{pcm}$.

\section{RESULTS}

The course of keff depending on the fuel assembly pitch in the TEPLATOR core, the fuel layer thickness, and the fuel layer material can be seen in Figure 4 and Figure 5. These courses were made for all six geometry fuel modifications, for each modification only some fuel layer thicknesses were considered.

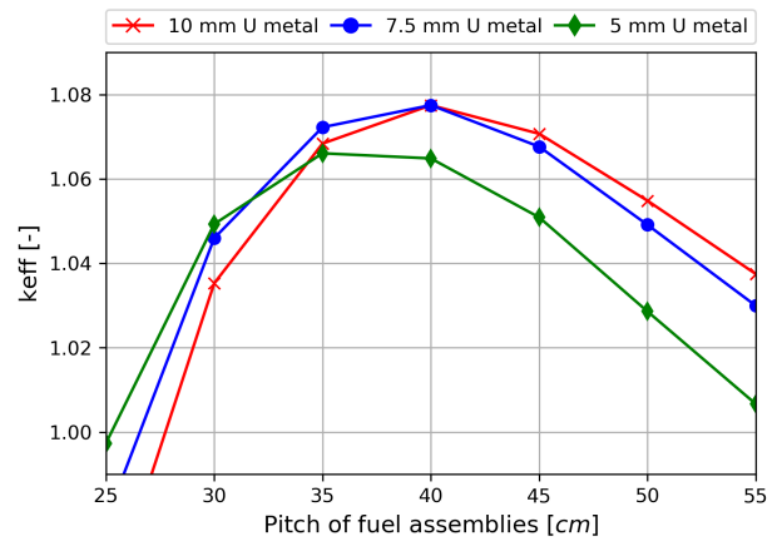

Figure 4. The results of keff for different fuel assembly pitch - one tubular tube geometry with metal uranium fuel layer

From the Figure 4 and Figure 5 can be seen, that the metal uranium reaches much higher keff compared to $\mathrm{UO}_{2}$ in all calculated cases for all fuel layer thicknesses. This trend can be observed for all fuel modifications, suggesting that uranium metal should be a more suitable fuel material for these purposes.

The second advantage of U-metal is that the thickness of the fuel layer is not problematic and the temperature peak inside the fuel layer is not so high due to thermal conductivity of U-metal. The metal uranium heat conductivity is slightly dependent on temperature, the thermal conductivity of uranium increases with increasing temperature. The heat conductivity at $20{ }^{\circ} \mathrm{C}$ is around $26 \mathrm{~W} / \mathrm{m} \cdot \mathrm{K}$, for $300{ }^{\circ} \mathrm{C}$ the conductivity rises up to $33 \mathrm{~W} / \mathrm{m} \cdot \mathrm{K}[6]$

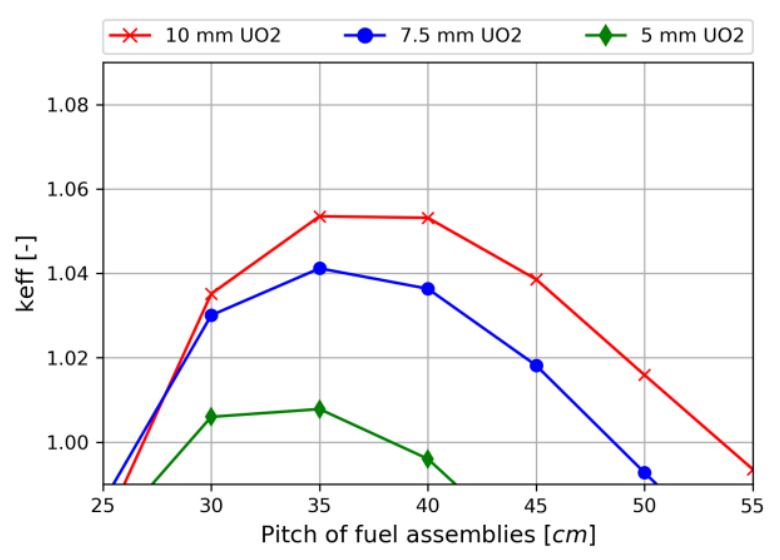

Figure 5. The results of keff for different fuel assembly pitch - one tubular tube geometry with UO2 fuel layer

The disadvantage of $\mathrm{UO}_{2}$ is that it has more than 8 times lower compared to $\mathrm{U}$ metal, so operating thicker layers than $10 \mathrm{~mm}$ of $\mathrm{UO}_{2}$ can be problematic. This is the reason why the $10 \mathrm{~mm}$ fuel layer was chosen as a maximal thickness for $\mathrm{UO}_{2}$ material. For metal uranium, in some special cases, $15 \mathrm{~mm}$ thickness of fuel layer is still possible to use.

Figures Figure 4 and Figure 5 prove that the reactivity at the beginning of the fuel cycle with fresh natural uranium fuel is sufficient for both fuel materials, and both fuel modification were recalculated by burnup sequence. Figure 4 and Figure 5 show the under-moderated region - on the left side from the maximal keff value for each case, and the over-moderated region on the right side from the optimal condition. The over-moderated modifications of fuel pitch cannot be used due to positive feedback during abnormal operation. For our burnup calculations, the optimal moderation point was chosen for each geometry. The optimal pitch of the fuel assemblies was chosen to be $40 \mathrm{~cm}$ for all cases.

The calculated results from burnup calculations for more promising fuel modifications are given in the tables below. The results for hexagonal fuel geometry with various number of fuel tubes and materials can be seen in Table 2 .

TABLE 2. CALCULATED BURNUP FOR HEXAGONAL FUEL GEOMETRY WITH THE DIFFERENT FUEL LAYER THICKNESS OF THE FUEL MATERIAL. THE PITCH OF THE FUEL ASSEMBLIES IS FOR ALL CASES SET TO $40 \mathrm{CM}$.

\begin{tabular}{ccccc}
\hline \hline $\begin{array}{c}\text { Number of } \\
\text { tubes and } \\
\text { material }\end{array}$ & $\begin{array}{c}\text { Fuel layer } \\
\text { thickness } \\
{[\mathrm{mm}]}\end{array}$ & $\begin{array}{c}\text { EFPD } \\
{[\text { days }]}\end{array}$ & $\begin{array}{c}\text { Fuel Weight } \\
{[\mathrm{kg}]}\end{array}$ & $\begin{array}{c}\text { Burnup } \\
{[\mathrm{MWd} / \mathrm{kgU}]}\end{array}$ \\
\hline 1 - metal & 10 & 2352.7 & 19177.7 & 6.15 \\
1 - metal & 7.5 & 1587.0 & 14622.8 & 5.42 \\
2 - metal & 6 & 2380.5 & 21302.6 & 5.58 \\
2 - oxide & 6 & 727.4 & 11815.8 & 3.07 \\
3 - metal & 3 & 1168.9 & 15430.7 & 3.77 \\
\hline \hline
\end{tabular}

From the Table 2 can be noticed that the highest burnup was reached for a single hexagonal tube with a $10 \mathrm{~mm}$ thick layer of U-metal fuel. Comparing burnup of single-tube modifications with various fuel thicknesses shows that the thicker layer is better than the thinner modification despite the previous criticality calculated results (from Figure 4 it is obvious that the maximum keff of both modifications reaches a very close value of keff around $40 \mathrm{~cm}$ pitch). This phenomenon is probably 
caused by different amount of uranium in the reactor core and the fact, that both modifications have a slightly different course of keff depending on the fuel assembly pitch. The layers with more than $10 \mathrm{~mm}$ fuel layer thickness were not considered as a suitable fuel geometry due to problematic fabrication, relatively high peak temperatures in the center of the fuel layer and due to huge amount of uranium per one loading.

The highest obtained burnup - 6.15 MWd/kgU was reached for one hexagonal tube modification with $10 \mathrm{~mm}$ fuel layer thickness. This modification can run for more than 6.44 years per one fuel loading at full output power - $50 \mathrm{MWth}$. The average fuel burnup $6.15 \mathrm{MWd} / \mathrm{kgU}$ is a slightly lower value of burnup than for commercially used CANDU fuel [7] . The burnup can be increased by using a Be reflector placed to special displacer in each fuel assembly, but this solution is very expensive so we did not consider it.

From the Table 2 can be noticed that using $\mathrm{UO}_{2}$ instead of metal uranium in two-tube case caused rapid fall of burnup and operation time per one loading. This behavior is valid for all $\mathrm{UO}_{2}$ cases. Using a $\mathrm{UO}_{2}$ as the fuel material is not economically reliable due to the low fuel utilization in this fuel geometry and core arrangement. The comparison between cylindrical and hexagonal modifications for the singe-tube case was done, and the comparison can be seen in Table 3 .

TABLE 3: COMPARISON OF HEXAGONAL (HEX) AND CYLINDRICAL (CYL) FUEL GEOMETRY WITH SAME FUEL LAYER THICKNESS.

\begin{tabular}{cccc}
\hline \hline Fuel modification & Weight of $\mathrm{U}[\mathrm{kg}]$ & keff [-] & $\begin{array}{c}\text { Burnup } \\
{[\mathrm{MWd} / \mathrm{kgU}]}\end{array}$ \\
\hline 1 CYL 10 mm & 17888.2 & 1.07748 & 5.68 \\
1 HEX 10 mm & 19177.7 & 1.07827 & 6.15 \\
\hline \hline
\end{tabular}

This table shows that the modification with hexagonal fuel shape is more promising than the cylindrical fuel shape. It can be caused by lower amount of fissile material in fuel assemblies and different geometry of fuel. To achieve the same amount of fuel, the fuel layer thickness should be higher. Advantage of hexagonal fuel shape compared to cylindrical fuel shape is fact that fabrication of hexagonal fuel is easier than cylindrical fuel. The fuel layer plates can be relatively simply cast as one uranium plate with corresponding dimensions. This plate can be inserted to the cladding box and tightly welded to prevent fission product release. After that, the hexagonal fuel assembly can be composed of six independent fuel plates with cladding, which can be welded to one fuel assembly. This method can be applicable for all hexagonal geometries with different number of fuel tubes.

The Figure 6 shows the keff course during reactor operation for different hexagonal fuel geometry for imagination.

Based on the Figure 6 the different operation time should be observed for changing the number of fuel tubes in one fuel assembly. It appears that the two-tube modification, the blue curve in Figure 6, has a longer operation time, which aims to achieve higher burnup and fuel utilization than for the one-tube modification, the green curve. In fact, more than $2.000 \mathrm{~kg}$ of uranium fuel is in two-tube modification compared to one-tube modification, which implicate a lower fuel burnup. Table 2 presents the reached burnup, operation time and other

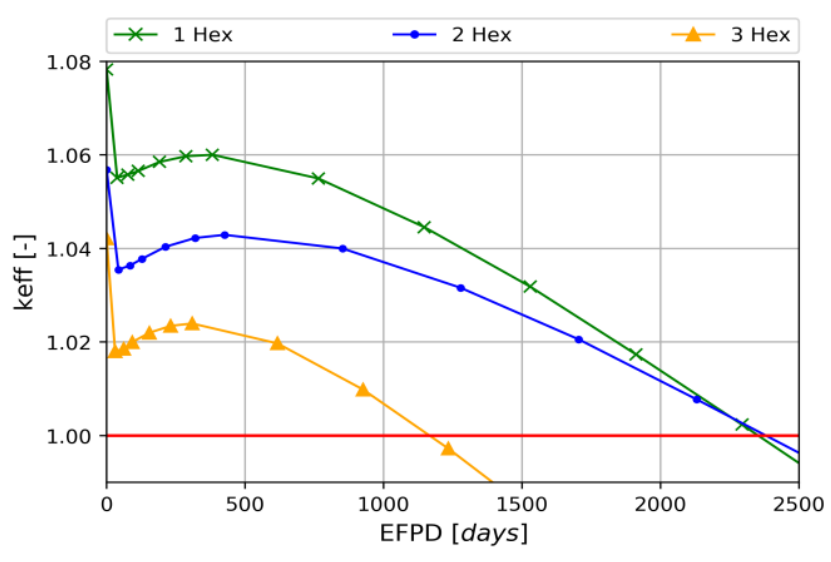

Figure 6: Comparison of keff courses and full power operation time for three cases of hexagonal fuel geometries with one hexagonal tube (1 HEX), two tubes $(2 \mathrm{HEX})$ and three tubes ( 3 HEX)

information for the main calculated cases.

The motivation for calculations with more than one-tube fuel modifications is that when we would like to use this type of fuel for next TEPLATOR units with higher thermal output power, the one-tube modification cannot be used due to relatively high heat flux per one square meter. This problem is reduced using two or three-tube geometries. Using more than three concentric tubes with thinner fuel layers is not possible due to insufficient excess of reactivity at the beginning of the fuel cycle. This phenomenon is probably caused by self-shielding and higher amount of non-fissile material per fuel assembly. Higher fuel utilization is achieved with two-tube modification compared to three-tube modification, see Table 2.

After all these calculations we verified our results for new developed fuel geometries. We calculated two cases using a standard CANDU fuel geometry. The case was calculated with standard CANDU fuel bundles with natural $\mathrm{UO}_{2}$ enrichment, which were placed in TEPLATOR fuel channels. The second option used a CANDU geometry, but the $\mathrm{UO}_{2}$ was replaced by U-metal. We recalculate the results for these calculations, which can be seen in Table 4.

TABLE 4: CALCULATED BURNUP FOR THE CANDU FUEL GEOMETRY WITH DIFFERENT FUEL MATERIALS. THE PITCH OF THE FUEL ASSEMBLIES IS SET TO

\begin{tabular}{cccc}
\multicolumn{4}{c}{$35 \mathrm{CM}}$. \\
\hline \hline \multirow{2}{*}{ Fuel material } & EFPD [days] & $\begin{array}{c}\text { Fuel weight } \\
{[\mathrm{kg}]}\end{array}$ & $\begin{array}{c}\text { Burnup } \\
{[\mathrm{MWd} / \mathrm{kgU}]}\end{array}$ \\
\hline $\mathrm{UO}_{2}$ & 690.1 & 12613.7 & 2.7 \\
U-metal & 1412.8 & 22741.0 & 3.1 \\
\hline \hline
\end{tabular}

Comparison of the results of achieved burnup for CANDU fuel and the results of the newly developed tube geometries shows that the new fuel design is more suitable for TEPLATOR and achieves higher burnup than the CANDU fuel. Reaching higher burnup than for the CANDU fuel type proves that using this new developed type of fuel is more meaningful in terms of economy and uranium consumption.

\section{CONCLUSIONS}

This work focuses on the development of new natural uranium fuels for a new reactor design, the TEPLATOR. Sets 
of calculations in Serpent code were performed for verification of preliminary results. The new developed fuel geometries were tested with different fuel assembly pitches in TEPLATOR core for finding an optimal fuel channel pitch for safety and economic reasons. After that, the burnup calculations were done for more promising modifications with higher keff.

The burnup calculation shows that the use of natural uranium in metallic form is possible and economically sustainable. The best fuel arrangements in the form of single-hexagonal-tube with a $10 \mathrm{~mm}$ thick fuel layer of U-metal reach fuel burnup of more than $6 \mathrm{MWd} / \mathrm{kgU}$. This burnup is quite high, considering the size of the entire reactor core, the amount of natural uranium and construction of the TEPLATOR core. This type of fuel can be marked as an alternative fuel for TEPLATOR.

The following research will be focused on deeper thermohydraulic analyses of the developed fuel and on following calculations of power distribution in the reactor core. The detailed behavior during fuel operation and the detailed burnup of the fuel will be determined.

\section{ACKNOWLEDGMENTS}

Research and Development has been funded by the Ministry of Education, Youth and Sports of the Czech Republic through the University specific research project no. SGS-2021-018.

\section{REFERENCES}

[1] J. Závorka, M. Lovecký, and R. Škoda, "Basic design of the TEPLATOR core - construction" in Proc. 29th International Conference Nuclear Energy for New Europe (NENE 2020). Ljubljana: Nuclear Society of Slovenia, 2020. s. 402.1-402.7. ISBN 978-961-6207-49-2.

[2] T. Peltan, E. Vilímová, and R. Škoda, "Natural uranium as alternative fuel for TEPLATOR". in: Proc. 29th International Conference Nuclear Energy for New Europe (NENE 2020). Ljubljana: Nuclear Society of Slovenia, 2020. s. 406.1-406.8. ISBN 978-961-6207-49-2.

[3] Special coolant displacer in nuclear fuel mitigating LOCA accident, by T. Peltan, E. Vilímová, R. Škoda (2020, March 20). Patent: PV 2020498

[4] J. Leppänen, M. Pusa, T. Viitanen, V. Valtavirta, and T. Kaltiaisenaho, "The Serpent Monte Carlo code: Status, development and applications in 2013," Ann. Nucl. Energy, vol. 82, pp. 142-150, 2015, doi: 10.1016/j.anucene.2014.08.024.

[5] M. B. et al. Chadwick, "ENDF/B-VII.1: Nuclear Data for Science and Technology: Cross Sections, Covariances, Fission Product Yields and Decay Data," Nucl. Data Sheets, vol. 112, 2011.

[6] L. H. Ortega, B. Blamer, K. M. Stern, J. Vollmer, S. M. McDeavitt, "Thermal conductivity of uranium metal and uranium-zirconium alloys fabricated via powder metallurgy" Jour. of Nucl. Materials, Vol. 531, 2020, ISSN 0022-3115, doi: 10.1016/j.jnucmat.2019.151982.

[7] B. Rouben, "CANDU Fuel-Management Course" Atomic Energy of Canada Ltd. 